\title{
PERFORMANCE OF THE ADVANCED PHOTON SOURCE (APS) LINAC BEAM POSITION MONITORS (BPMS) WITH LOGARITHMIC AMPLIFIER ELECTRONICS*
}

\author{
R. E. Fuja and M. White \\ Argonne National Laboratory, 9700 S. Cass Avenue, Argonne, Il 60439 USA
}

\section{Abstract}

This paper discusses the performance of the logarithmic amplifier electronics system used with stripline BPMs to measure electron and positron beam positions at the APS linac. The 2856- $\mathrm{MHz}$, S-band linac accelerates 30-nsec pulses of $1.7 \mathrm{~A}$ of electrons to $200 \mathrm{MeV}$, and focuses them onto a positron conversion target. The resulting $8 \mathrm{~mA}$ of positrons are further accelerated to $450 \mathrm{MeV}$ by the positron linac. Beam position resolutions of $50 \mu \mathrm{m}$ are easily obtainable in both the electron and positron linacs. The resolution of the 12-bit AVD converters limits the ultimate beam positron resolution to between 20 and $30 \mu \mathrm{m}$ at this time.

\section{INTRODUCTION}

The APS linac BPM system, in operation for over a year, has been used in the commissioning of both the $200 \mathrm{MeV}$ electron and the $450-\mathrm{MeV}$ positron beams. It consists of stripline pickups and signal processing electronics using logarithmic amplifiers. The system has proven very reliable with only one problem occurring in an A/D section. System stability has not been a problem, and beam can be transported to the end of the linac a few minutes after being turned on.

\section{EXPERIMENT}

The following data were taken to determine the resolution of the linac BPM system in the presence of pulsed power supply noise. Background on the detectors and the processing electronics is provided.

\section{A. Detectors}

Stripline-type BPMs [1], were chosen because they provide $-5 \mathrm{dBm}$ of peak signal from the $8-\mathrm{mA}$ positron beam. The BPMs are cylindrical in geometry, and the four striplines are mounted 90 degrees apart. The striplines are 1 inch long and subtend an arc of 1 radian. Their geometry is such that they form 50-Ohm pickups. The measured electrical length of the striplines is 0.21 wavelengths at $2.856 \mathrm{GHz}$. The average detector sensitivity is $1.73 \mathrm{~dB} / \mathrm{mm} \pm 0.1 \mathrm{~dB}$. Signals from the striplines are transported via $1 / 4$-inch heliax cable to electronics located an average of 85 feet away in the klystron gallery. About $10 \mathrm{~dB}$ of signal is lost over this distance.

* Work supported by U.S. Department of Energy, Office of Basic Energy Sciences, under Contract No. W-31-109ENG-38.
Five BPMs are installed in the electron linac, one downstream of each accelerating structure, and seven BPMs are installed in the positron linac, one downstream of each of the last seven accelerating structures. There are no BPMs downstream of the first two accelerating structures after the target in the positron linac.

\section{B. Electronics}

The electronics [2], can be subdivided into two sections, a downconverter section and a logarithmic amplifier section. The downconverter section consists of a $2.856-\mathrm{GHz}$ to $70-\mathrm{MHz}$ downconverter followed by a $70-\mathrm{MHz}$ bandpass filter and amplifier. The bandpass filter stretches the 30-nsec pulse to around $200 \mathrm{nsec}$ and reduces its amplitude by some $13 \mathrm{~dB}$. The overall gain of the downconverter is around 6.2 $\mathrm{dB}$ and it has a noise figure of around $7.5 \mathrm{~dB}$. This $70-\mathrm{MHz}$ signal is used as the input to a cascaded chain of logarithmic amplifiers consisting of two Analog Devices AD640s with their video bandwidths set to $7 \mathrm{MHz}$. The input power to the logarithmic amplifiers is adjusted to $-10 \mathrm{dBm}$ for the two different beam intensities in the electron and positron linacs. The sensitivity of the logarithmic amplifier chain is 53 $\mathrm{mV} / \mathrm{dB} \pm 1 \mathrm{mV}$. The calibration shown in Figure 1 is typical of all logarithmic amplifier sections.

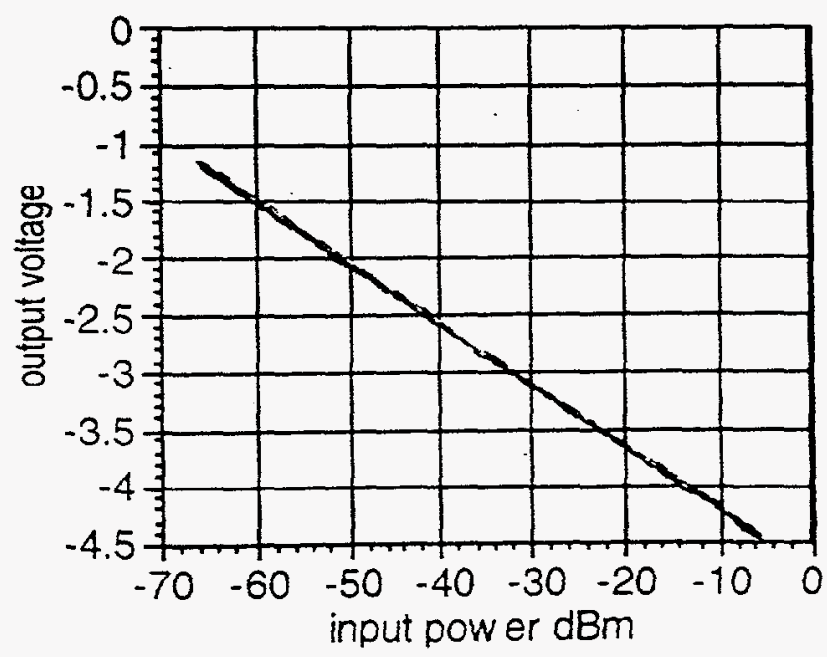

Figure 1: Dynamic ranges of eight different logarithmic amplifier channels. The slope is $-54.26 \pm 0.6 \mathrm{mV} / \mathrm{dBm}$, and the intercept is at $-4.756 \pm 0.02 \mathrm{~V}$. 


\section{DISCLAIMER}

This report was prepared as an account of work sponsored by an agency of the United States Government. Neither the United States Government nor any agency thereof, nor any of their employees, make any warranty, express or implied, or assumes any legal liability or responsibility for the accuracy, completeness, or usefulness of any information, apparatus, product, or process disclosed, or represents that its use would not infringe privately owned rights. Reference herein to any specific commercial product, process, or service by trade name, trademark, manufacturer, or otherwise does not necessarily constitute or imply its endorsement, recommendation, or favoring by the United States Government or any agency thereof. The views and opinions of authors expressed herein do not necessarily state or reflect those of the United States Government or any agency thereof. 


\section{DISCLAIMER}

Portions of this document may be illegible in electronic image products. Images are produced from the best available original document. 
Eight logarithmic amplifier channels are mounted on a single VXI card and process the signals from two BPMs. The VXI card also contains eight sample and hold circuits and eight 12-bit analog-to-digital converters. A specially designed VXI trigger module [3] contains a set of 8-bit programmable delay lines that can be used to select sample times in increments of $5 \mathrm{nsec}$. Software peak detection by scanning is available for all BPM signals, replacing the more commonly used peak detection circuits.

With a detector sensitivity of $1.73 \mathrm{~dB} / \mathrm{mm}$ and a logarithmic amplifier sensitivity of $53.3 \mathrm{mV} / \mathrm{dB}$ the overall sensitivity of the system becomes $94 \mathrm{mV} / \mathrm{mm}$. The gain of each downconverter channel was adjusted by injecting a $2.856-\mathrm{GHz}$ signal into the cable at the detector end and adjusting the amplitude of the $70-\mathrm{MHz}$ output. Phase shifters at the input to the downconverter enabled the phase between two 70-MHz output signals to be matched. Zeroing the phase shifts was necessary because of coherent noise in the system; $5 \mathrm{mV}$ corresponds to $53 \mu \mathrm{m}$. The signal difference for two typical channels is shown in Figure 2.

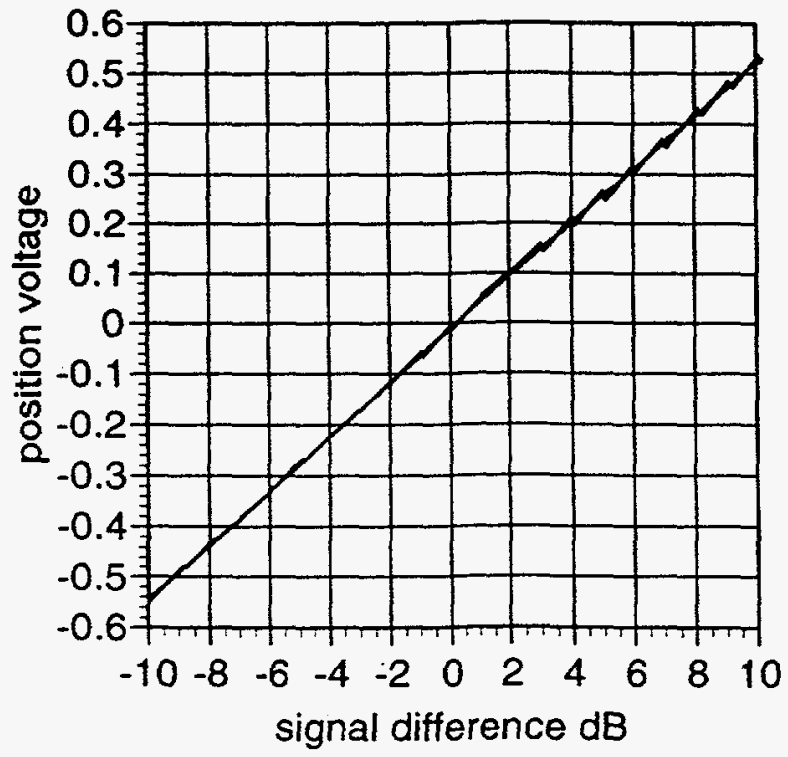

Figure 2: Signal difference between 2 channels for input power levels of $-15,-25$, and $-35 \mathrm{dBm}$. The slope is 53.31 $\mathrm{mV} / \mathrm{dB}$ and the offset is $-10.2 \mathrm{mV}$.

\section{RESULTS}

The results presented below were obtained during a positron studies run and they are the best to date. Typically, operating conditions result in data from selective positron linac BPMs that are up to five times worse. Electron linac BPMs consistently provide good data because the signals are large. The results from positron linac BPMs vary because both electrons and positrons are present in a ratio that depends on the particular transport optimization at the time. The amplitide of the signal they receive depends on the magnitude of the charge difference between electrons and positrons. The charge of the particle that is present in excess is unknown and must be determined by other means. Figure 3 shows data taken from the BPM located just upstream of the positron target, when $1.06 \mathrm{~A}$ of electrons were hitting the target. With 16 samples, the standard deviation of the readings from individual electrodes is 5 to $7 \mathrm{mV}$ and the standard deviation in the difference of two signals is 1 to 2 $\mathrm{mV}$, corresponding to $21.3 \mu \mathrm{m}$. Figure 4 shows BPM data from the detector furthest downstream in the positron linac. Here the intensity reading is $6 \mathrm{~mA}$ and represents the magnitude of the sum of the positron and electron currents in the beam. Other measurements made in the low energy transport line after a bending magnet indicate that $4 \mathrm{~mA}$ of positrons were present at that time. Here the standard deviation in the position measurement is $3 \mathrm{mV}$ or $33 \mu \mathrm{m}$.

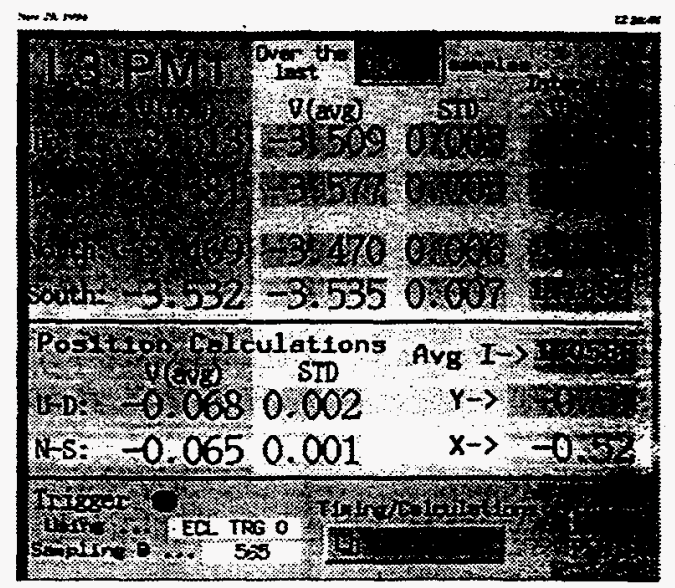

Figure 3: Data taken from the BPM located just upstream of the positron target, when $1.06 \mathrm{~A}$ of electrons were hitting the target.

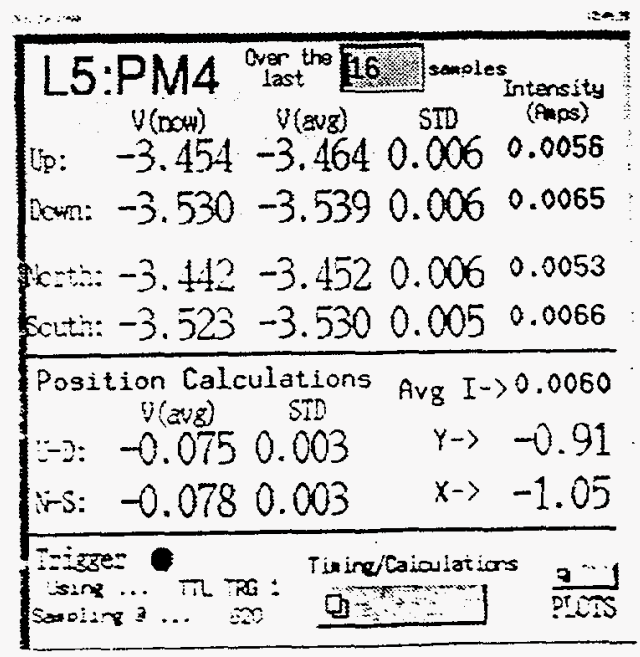

Figure 4: BPM data trom the last detector in the positron linac. Here the intensity reading is $6 \mathrm{~mA}$. the magnitude of the sum of the positron and electron currents. 


\section{CONCLUSION}

With proper phasing of the stripline signals it is not difficult to obtain the results shown. With the signal-to-noise ratio at the input to the logarithmic amplifier circuits approaching $75 \mathrm{~dB}$, resolutions of $1 \mu \mathrm{m}$ should be possible.

$A$ new $B P M$ system that gives information on the polarity of the charged particle producing the signal (electron or positron) has been worked out, and will provide for much improved positron diagnostics capability [4]. A prototype is under development.

\section{ACKNOWLEDGEMENTS}

The authors would like to thank C. Gold for his help in the laboratory and in the installation, J. Stephens for his help with the software testing programs, and N. Amold and K. Ko for developing the control systems and operating screens.

\section{REFERENCES}

[1] R. Shafer, "Beam Position Monitoring," Accelerator Instrumentation, Upton, N.Y., 1989, AIP Conference Proceedings 212, pp. 26-58, (1989).

[2] R. Fuja and Y. Chung, "The APS Linac Beam Position Monitor and Electronics," Proc. of the 4th Accel. Instr. Workshop, Berkeley, CA., October 1992, AIP Conference Proceedings No. 281, pp. 248-255 (1993).

[3] A.E. Grelick, private communication.

[4] W. Sellyey, private communication. 